\title{
Test Profiles of Broiler Breeder Flocks Housed in Farms with Endemic Mycoplasma synoviae Infection
}

Author(s)

Fiorentin $\mathrm{L}^{1}$

Mores $\mathrm{MAZ}^{2}$

Trevisol IM ${ }^{2}$

Antunes SC

Costa JLA ${ }^{2}$

Soncini RA ${ }^{2}$

Vieira ND ${ }^{1}$

1- Embrapa Suínose Aves

2 - Sadia SA

\section{ABSTRACT}

There is a need for a better understanding of the epidemiology of $M$ ycoplasma synoviae (MS) infection in broiler breeders in Brazil. M any features of the infection remain unrecognizable, because there are no clinical signs of the disease. A detailed testing was performed at each 6 to 8 weeks in three MS-free flocks introduced in farms with endemic MS infection for a follow-up epidemiological study. Every flock was monitored by polymerase chain reaction (PCR), by serum plate agglutination (SPA) and hemagglutination inhibition $(\mathrm{HI})$ for serology studies, and isolation of mycoplasmas from tracheal swabs. PCR was found to be the most sensitive test, detecting early M S infection. Serology was positive in less than $50 \%$ of the sera and MS was isolated only between 27 and 28 weeks of age and in a maximum of $60 \%$ positive hens. A similar profile was seen for MS infection in all three flocks. Infection started at brooding, whereas laboratory detection of the assymptomatic infection was more probable in the weeks of increasing egg production. This predictable profile during rearing may be very useful for the optimization of monitoring MS infection in broiler breeder flocks.

\section{INTRODUCTION}

M ycoplasma synoviae (MS) causes a respiratory infection in chickens that is sub-acute most of the times. It also causes assymptomatic synovitis frequently. Progeny might be infected by vertical transmission, due to the contamination of fertile eggs, and thus the control of MS infection includes rearing birds that are obtained preferably from MS-free breeders. These MS-free birds are, consequently, reared with rigorous biosecurity measures in order to prevent lateral contamination, where other birds are the primary source of infection (Kleven, 1997). In some instances, parents and grandparents are slaughtered if they become infected, so that MS dissemination can be prevented.

Free-MS certification in a basic line flock of birds is thus definite for the control of the pathogen. This might not be simple in many cases, since usually no clinical signs are apparent, labo ratory tests must be highly reliable. They must be sensitive enough to prevent false-negative results, but also specific enough so as not to result in false-positives (Kleven, 1997). False results, also, may occur if the birds are not tested in a period when the agent is active. In that case, even tests with a good sensitivity produce unreliable results. As a result, both the maintenance of breeder flocks with false negative results and the elimination of a M S-free flock with false positive results in monitoring, will cause considerable losses to poultry industry.

Laboratory detection of MS infection is made by techniques with internationally accepted standardization (Kleven, 1998). Serum plate 
agglutination (SPA), hemagglutination inhibition $(\mathrm{HI})$ and ELISA are the most common serological techniques. Direct diagnosis requests isolation and identification of the agent in selective culture media (Kleven, 1997) or the demonstration of the DNA of the pathogen in the host using the polymerase chain reaction (PCR) (Lauerman et al., 1993).

Field observations have suggested that detailed information about MS infection in broiler breeders in Brazil should be obtained and might be helpful in monitoring the agent and increasing the reliability when decisions are to be taken. M any times, breeder flocks are originated from M S-free grandparent flocks and are reared in an infected farm. Although the breeder flocks are kept in isolated poultry houses, they become serologically reactive. Consequently, the beginning of the infection cannot be defined and biosecurity measures are more difficult to be implemented. In such cases, it is possible that fertile egg production can be managed as if they were from aM ycoplasma-free flock for many w eeks. In other cases, isolation of the pathogen is virtually impossible in flocks that are serologically reactive, even when the laboratory conditions are adequate. This suggests that the success of pathogen isolation might depend on the sampling, which might have to be done in a short period of time. MS-free farms may also become suddenly positive, and the source of infection may not be identified in order to guide biosecurity efforts. Another aspect of diagnosis is that serological tests do not always show the same result and SPA seems to have low sensitivity in some situations (Ewing et al., 1998).

The results obtained here suggest that MS infection in broiler breeders introduced in endemic farms have a defined profile. Infection during rearing was predictable and there were no signals and lesions, nevertheless laboratory detection was facilitated in the first weeks of egg production. These might be important results in order to define control strategies both for the poultry industry and for governmental MS control in Brazil.

Table 1 - Age of sampling for each studied flock.

\begin{tabular}{lccccc} 
Flocks & \multicolumn{5}{c}{ Age (w eeks) } \\
\hline $31 / 01$ & 6 & 15 & 22 & 27 & 34 \\
\hline $53 / 00$ & $\mathrm{NP}^{1}$ & 11 & 21 & 27 & 32 \\
\hline $59 / 00$ & 8 & 12 & 28 & 28 & 33 \\
\hline
\end{tabular}

1-Not performed.

\section{MATERIAL AND METHODS}

\section{Birds}

Grand parents were considered negative for M S and $M$ ycoplasma gallisepticum based on many consecutive negative serological results, isolation and PCR attempts, and also because they had been housed in a farm with no infection report. The eggs originated from the grandparents hatched in a single hatchery, avoiding any possible contamination from eggs originated from other flocks that might be MS-positive. Three flocks were produced with approximately 12 thousand broiler breeders (Table 1), which were housed in poultry houses from different places of a rearing farm endemic for MSinfection. Birds were reared until the $21^{\text {st }}$ week of age and where then transferred to production farms that, also, had infection report.

\section{Flocks follow -up}

Besides routine evaluation for detection of any clinical signs, samples of blood and tracheal swabs were collected from each flock at intervals of approximately 6 to 8 weeks. Sampling was maintained till the flocks could be unequivocal ruled as positive, followed by a confirmatory sampling 6-8 weeks later (Table 2).

\section{Serology}

Plate serum agglutination (SPA) was performed in the support laboratory of the farm. Fifteen to thirty undiluted fresh serum samples were tested with a commercial antigen (Intervet International, B.V., Boxmeer, Holland), used according to the manufacturer's instructions (readings within 2 min). Positive sera for SPA were taken to the Central Laboratory of Sadia S.A., Concórdia, SC, and submitted to hemagglutination inhibition test $(\mathrm{HI})$ using the antigen produced in the laboratory. Sera were considered positive when titration was equal or higher than 80 (Kleven, 1998).

Table 2 - Flocks age (weeks) when M S-positive tests were detected

\begin{tabular}{lcccc} 
Flocks & PCR & Isolation & PSA & HI \\
$31 / 01$ & 27 & 27 & 22 & 27 \\
$53 / 00$ & 11 & 27 & 32 & 32 \\
$59 / 00$ & 22 & 28 & 22 & 33 \\
\hline
\end{tabular}


Fiorentin L, Mores MAZ, Trevisol IM, Antunes SC, Costa JLA, Soncini RA, Vieira ND
Test Profiles of Broiler Breeder Flocks Housed in Farms with Endemic Mycoplasma synoviae Infection

\section{Polymerase chain reaction (PCR)}

Tracheal swabs were obtained from 10 birds per flock in each sampling, at ages indicated in Table 1. The samples were used in a polymerase chain reaction (PCR) to detect MS, in the laboratory of Embrapa Suínos Aves, in Concórdia, SC, according to the technique described by Lauerman et al. (1993). Swabs with plastic stem and cotton tip was introduced within the trachea, the cotton tip was immediately immersed in $0.5 \mathrm{~mL}$ of phosphate buffered saline (PBS; $150 \mathrm{mM}$ $\mathrm{NaCl}, 2.6 \mathrm{mM} \mathrm{NaH}_{2} \mathrm{PO}_{4}, 7.4 \mathrm{mM} \mathrm{Na}_{2} \mathrm{HPO}_{4}, \mathrm{pH} 7.5$ ) and sent to the laboratory under refrigeration. This procedure has been described as adequate for sampling and samples were sent to PCR analysis (Silveira et al., 1996). After shaking vigorously and boiling for $5 \mathrm{~min}$, five micro liters of the buffer was used in the PCR, with $5 \mu \mathrm{L}$ of sample; $1 \mu \mathrm{L}$ of the primer $(5 \mathrm{pM})$ 5 '-d[GAGAAGCAAAATAGTGATATCA ]3'; $1 \mu \mathrm{L}$ of the primer (5pM) 5'-d[CAGTCGTCTCCGAAGTTAACAA]3'; and $14 \mu \mathrm{L}$ of a pre-mixture containing $10 \mathrm{mM}$ Tris- $\mathrm{HCl}$ $\mathrm{pH} 9.0 ; 50 \mathrm{mM} \mathrm{KCl} ; 1.5 \mathrm{mM} \mathrm{MgCl} ; 200 \mu \mathrm{M}$ of each deoxyribonucleoside triphosphate (dATP, dCTP, dGTP and (TTTP), water and $1.5 \mathrm{U}$ of Taq polymerase, in a total reaction volume of $25 \mu \mathrm{L}$. The tubes were centrifuged for $30 \mathrm{~s}$ at $12,000 \times \mathrm{g}$ and denatured for one minute at $94^{\circ} \mathrm{C}$, following 40 cycles of 30 seconds at $94^{\circ} \mathrm{C}, 55^{\circ} \mathrm{C}$ and $72^{\circ} \mathrm{C}$, and a final cycle of 5 minutes at $72^{\circ} \mathrm{C}$. A positive control ( $\mathrm{M} \mathrm{S}$ culture) and a negative control (all components except DNA) were added to each reaction. Amplified fragments were submitted to electrophoresis (110V/45 $\mathrm{min}$ ) in a $2 \%$ agarose gel in TE buffer (10mM Tris-HCl, 1mM EDTA, pH 7.5), and stained with ethidium bromide $(10 \mu \mathrm{g} / \mathrm{mL}$ in TE buffer) to compare with the pattern of the reference samples and a $100 \mathrm{bp}$-molecular weight standard. Samples were considered positive when a DNA fragment with approximately 206 bp was obtained.

\section{Mycoplasma isolation}

Tracheal swabs were individually collected from 10 birds in each sampling and each age (Table 1). After sampling, the swabs were introduced in tubes containing Frey broth (Freyet al., 1968) with 12\% swine serum supplemented with $0.1 \mathrm{~g} / \mathrm{L}$ of nicotinamide adenine dinucleotide (NAD) and $0.1 \mathrm{~g} / \mathrm{L}$ of cysteine hidrochloride hydrate, necessary for MS growth, besides $1,000,000 \mathrm{IU}$ penicillin $\mathrm{G}$ and $0.25 \mathrm{~g}$ of thalium acetate per liter, to prevent opportunistic bacterial growth. Tubes were vigorously shaken and swabs were discarded before the samples were sent, on ice, to the laboratory. Samples were incubated in a microanaerobiosis chamber at $37^{\circ} \mathrm{C}$. Aliquots of each culture showing acidification or turbidity in the broth, indicative of mycoplasma growth, were plated in Frey agar (Frey broth with $0.75 \%$ agarose), every seven days for three consecutive times. After 21 days, cultures that show ed no colonies on the agar were discarded as negative. All isolated mycoplasmas were submitted to colony immunofluorescence, using serum of rabbit immunized with the reference sample MS WVU 1853 and labeled with fluorescein isotiocyanate (Bradbury, 1998).

Each MS isolate was cloned three times as follow s: one colony was collected from the Frey agar plate to produce a liquid culture by incubating for 4 to 5 days in $1 \mathrm{~mL}$ Frey broth; then, filtered in a $0.45 \mu \mathrm{m}$ filter, diluted and plated in Frey agar to obtain new isolated colonies, and successively for three times (Kleven, 1998). After the third cloning, cultures were confirmed as MS using PCR, identified by the lot number or the laboratory protocol and stored at $-80^{\circ} \mathrm{C}$ until necessary.

\section{DNA extraction and Random Amplified Polymorphic DNA Analysis (RAPD)}

The different MS isolated samples and the reference sample MSWVU 1853 were cultured in $25 \mathrm{~mL}$ Frey broth for $24 \mathrm{~h}$ at $37^{\circ} \mathrm{C}$ and cells were collected by centrifugation at approximately $12,000 \times \mathrm{g}$ for $15 \mathrm{~min}$. The pellet was washed with PBS pH 7.4 and centrifuged for three times. In the last wash, the pellet was ressupended in $2 \mathrm{~mL}$ of TE (0.01M Tris-HCl; 0.01M NaCl; 0.01M EDTA; pH 8.0). DNA was purified by phenol extraction (Bashirudin, 1998) and submitted to RAPD (Leyet al., 1998). RAPD analysis used $1 \mu \mathrm{L}$ of primer (25pM) 5'-d[GTAGACCCGT]3' (Amersham Pharmacia Biotech) and $1 \mu \mathrm{L}$ DNA (50 ng) per reaction. Tests were conducted in tubes containing the other reaction components (Ready-To-Go RAPD Analysis Beads, Amersham Pharmacia Biotech; with AmpliTaq polymerase and Stoffel fragment, $0.4 \mathrm{mM}$ of each dNTP, $2.5 \mu \mathrm{g}$ of bovine serum albumin, $3 \mathrm{mM} \mathrm{M} \mathrm{gCl}$, $30 \mathrm{mM} \mathrm{KCl}, 10 \mathrm{mM}$ Tris, $\mathrm{pH} 8.3$, previously diluted in $23 \mu \mathrm{L}$ ultra-pure water) using 4 cycles at $94^{\circ} \mathrm{C}$ for $5 \mathrm{~min}, 36^{\circ} \mathrm{C}$ for $5 \mathrm{~min}$ and $72^{\circ} \mathrm{C}$ for $5 \mathrm{~min}$, followed by 30 cycles at $94^{\circ} \mathrm{C}$ for one min, $36^{\circ} \mathrm{C}$ for one min and $72^{\circ} \mathrm{C}$ for one min, and a final cycle at $72^{\circ} \mathrm{C}$ for $10 \mathrm{~min}$ for final extension of DNA. The amplified DNA fragments were submitted to electrophoresis (110V/90 $\mathrm{min}$ ) in a $2 \%$ agarose gel in TE buffer (10mM Tris-HCl, 1mM EDTA, pH 7.5), stained with ethidium bromide (10 $\mathrm{gg} / \mathrm{mL}$ in TE buffer) and the profiles were photographed for comparison. The DNA 
Fiorentin L, Mores MAZ, Trevisol IM, Antunes SC, Costa JLA, Soncini RA, Vieira ND

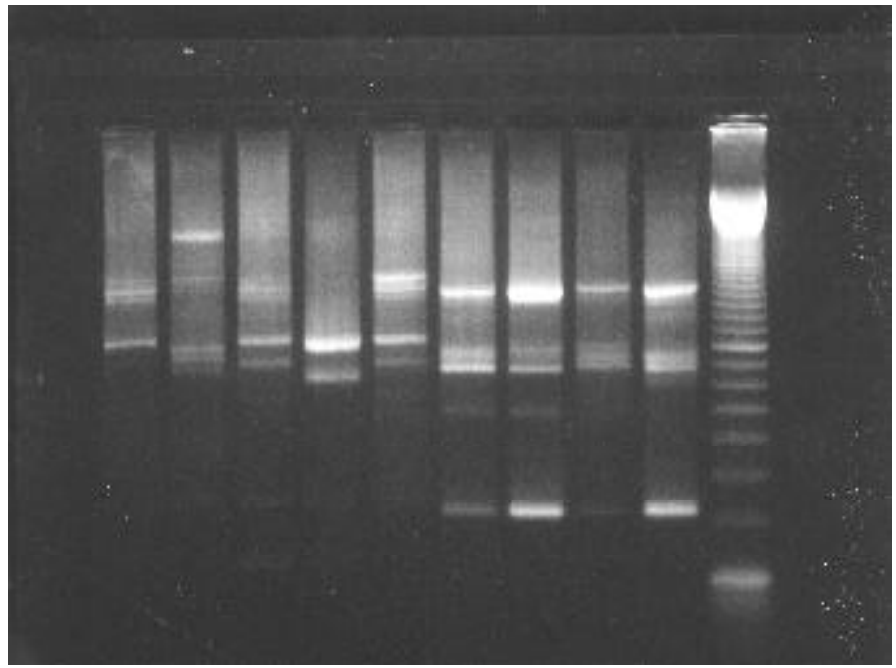

Figure 1 - RAPD profile of MS isolated. From left to right are the reference strain MS WVU and MS H, isolates M S 155, MS 443 and MS 35 obtained from other sources and M S 541, MS 542, MS 53 and MS 59 isolated in the present work. The last lane show s 100-bp standards.

of the vaccine sample M SH was kindly provided by Dr. Phillip F. Markham, from the University of M elbourne, Australia (M orrow et al., 1998b).

\section{Pathogenicity of MS for SPF birds}

A sample obtained from the same farm and with a RAPD profile identical to those from the studied flocks (M S 541, Figure 1) was used for experimental infection. Eight SPF chicks (Spafas) were placed in an isolator with air filter, fed an antibiotic-free diet and inoculated in the $15^{\text {th }}$ day of life with $0.1 \mathrm{~mL}$ of a 24 -hour culture in Frey broth, containing approximately $10^{11} \mathrm{CFU}$. The inoculum was sprayed onto the choanal cleft for aspiration. Four weeks later (sixth week of life), all birds were sacrificed, and sera were submitted to serology, PCR and isolation technique. Independent swabs w ere collected from the trachea, air sacs and from the tarsusmetatarsial joint for PCR and M S isolation, and tested as described before. Samples from internal organs and the extensor metatarsal tendon were collected for histology (Luna, 1968).

\section{RESULTS AND DISCUSSION}

\section{Flockshistory}

The grandparents used to produce the studied flocks showed no positive results in any SPA or HI
Test Profiles of Broiler Breeder Flocks Housed in Farms with Endemic Mycoplasma synoviae Infection

tests performed at approximate intervals of 6 weeks throughout rearing and production periods. Nevertheless, 10 tracheal swabs were collected from the grandparents at 19, 33 and 66 weeks of age and individually tested using PCR. All of them confirmed the negative results of the flocks for MS. These results, together with the incubation of the eggs in an single hatchery assured that the chicks were MS-free when housed.

No clinical signs were observed in the breeders throughout the experiment. Differences in MS virulence may be experimentally detected (Fiorentin et al., 1991; Lockaby et al., 1998), suggesting the existence of samples with higher or lower virulence. The results from the present investigation suggest that the infecting MS present in this farm has a very low virulence for broiler breeders, or that it needs some external factor to fully express its pathogenicity, and such factor was not present.

\section{Serology}

All three breeder flocks were positive in SPA and $\mathrm{HI}$ for MS before egg production was increasing, i.e., between 22 and 32 weeks of age. Nevertheless, it was noticed that a low number of sera were reactive in SPA, although the same sera were confirmed as positive by showing titration in $\mathrm{HI}$ testing (Tables 3, 4 and 5). The delayed serological response detected in two flocks, which became positive by PCR only after 7 and 16 weeks, together with the low reactive number of sera, indicates that the sensitivity of SPA is below than expected and should be carefully evaluated when establishing an epidemiological surveillance program for MS. It has been suggested previously that MS surveillance should not be exclusively based in SPA, but it should be supported by PCR and attempts to isolate the agent (Ewing et al., 1998).

\section{Mycoplasma isolation}

MS was the only microorganism isolated from the tracheal swabs analyzed. In this study, there was no occurrence of other mycoplasmas from the trachea of the birds, such as M ycoplasma gallinarum, M ycoplasma gallinaceum and Mycoplasma pullorum, as previously reported (Bencina et al, 1987; Povedaet al, 1990). Other mycoplasmas with faster grow th are one of the possible reason for failure in MS isolation. Although no inference can be made on the presence or absence of other mycoplasmas in the trachea of the studied birds, their 
apparent absence in the swabs was responsible for the reasonable levels of isolation $(40 \%$ to $60 \%$ of the swabs between the $26^{\text {th }}$ and the $28^{\text {th }}$ weeks of life, Tables 3, 4 and 5).

MS isolation was obtained only between the $27^{\text {th }}$ to $28^{\text {th }}$ weeks of age suggesting that failures in mycoplasma isolation may be influenced by factors that are not generally considered. Thus, tracheal infection caused by MS can be latent in birds submitted to low stress level, such as that found during brooding or rearing.

During husbandry stressful situations, pre-laying vaccinations and the beginning of egg production, the infection may become acute and the number of viable mycoplasmas in the trachea increases, which facilitates the isolation in synthetic media.

MS isolation was not perfectly correlated to serology data. Isolation was seen at 27 weeks in one flock (Flock 53), whereas serology tests were positive at 32 w eeks of age. In another flock, serology was positive at 22 weeks of age but isolation was only seen at 28 weeks of age. This observation is important to re-evaluate the common practice of trying to isolate MS only if serology results become positive. In turkeys, it has been observed that the serology response to M S infection can be very weak and that isolation of the agent might be very difficult (Kleven et al., 2001). Immunosuppression caused by Infectious Bursal Disease Virus aggravates the lesions caused by MS (Giambroneet al., 1977). Different degrees of temporary immunosuppression might have allowed a higher invasion of MS, and a consequent positive serological responsea posteriori.

\section{PCR}

PCR was the most sensitive test, detecting the infection in two flocks (Flocks 59 and 53) 5 and 16 weeks respectively earlier than positive results were seen in the other tests (Tables 3, 4 and 5). Positive results for all 10 swabs in two samplings also suggest a high sensitivity of the PCR. A maximum of $60 \%$ swabs were positive for M S-isolation in some weeks, whereas $100 \%$ of the tested swabs were positive by PCR. There is the possibility that some birds showing negative results in PCR are positive in the M S isolation (Salisch et al., 1998); how ever, PCR seems to have higher sensitivity when samples are considered as a group. Maroiset al. (2000) reported that feces samples, feathers and dust collected from poultry houses with birds infected with MS may be positive by PCR. This finding strongly suggest a great probability of MS detection when swabs were collected from the trachea. This information, allied to the results obtained in this study, indicate for the necessity of adopting PCR as the routine technique in the epidemiological surveillance of MS in broiler breeders.

Table 3 - Positive samples/total samples for different tests at each sampling (Flock 31).

\begin{tabular}{lccccc} 
& \multicolumn{5}{c}{ Age (w eeks) } \\
\cline { 2 - 6 } Test & $\mathbf{6}$ & $\mathbf{1 5}$ & $\mathbf{2 2}$ & $\mathbf{2 7}$ & $\mathbf{3 4}$ \\
$\mathrm{PSA}$ & $0 / 20$ & $0 / 20$ & $2 / 30$ & $6 / 15$ & $1 / 15$ \\
$\mathrm{HI}^{2}$ & $\mathrm{NP}^{1}$ & $\mathrm{NP}$ & $\mathrm{NP}$ & $5 / 15$ & $1 / 15$ \\
$\mathrm{PCR}$ & $0 / 10$ & $0 / 10$ & $0 / 10$ & $10 / 10$ & $2 / 10$ \\
Isolation & $0 / 10$ & $0 / 10$ & $0 / 10$ & $6 / 10$ & $0 / 10$ \\
\hline
\end{tabular}

1- NP: Not performed.

2- HI was performed only in SPA-positive sera.

Table 4 - Positive samples/total samples for different tests at each sampling (Flock 53).

\begin{tabular}{lcccc} 
& \multicolumn{4}{c}{ Age (w eeks) } \\
\cline { 2 - 5 } Test & $\mathbf{1 1}$ & $\mathbf{2 1}$ & $\mathbf{2 7}$ & $\mathbf{3 2}$ \\
\hline $\mathrm{PSA}$ & $0 / 30$ & $0 / 30$ & $0 / 30$ & $2 / 30$ \\
\hline $\mathrm{HI}^{2}$ & $\mathrm{NP}^{1}$ & $\mathrm{NP}$ & $\mathrm{NP}$ & $2 / 2$ \\
\hline $\mathrm{PCR}$ & $6 / 10$ & $10 / 10$ & $4 / 10$ & $6 / 10$ \\
\hline Isolation & $0 / 10$ & $0 / 10$ & $5 / 10$ & $1 / 10$ \\
\hline
\end{tabular}

1- NP: Not performed.

2- HI was performed only in SPA-positive sera.

Table 5 - Positive samples/total samples for different tests at each sampling (Flock 59).

\begin{tabular}{lccccc} 
& \multicolumn{5}{c}{ Age (w eeks) } \\
\cline { 2 - 6 } Test & $\mathbf{8}$ & $\mathbf{1 2}$ & $\mathbf{2 2}$ & $\mathbf{2 8}$ & $\mathbf{3 3}$ \\
$\mathrm{PSA}$ & $0 / 30$ & $0 / 30$ & $1 / 30$ & $0 / 30$ & $1 / 30$ \\
$\mathrm{HI}^{2}$ & $\mathrm{NP}^{1}$ & $\mathrm{NP}$ & $0 / 1$ & $\mathrm{NP}$ & $1 / 1$ \\
$\mathrm{PCR}$ & $0 / 10$ & $0 / 10$ & $3 / 10$ & $10 / 10$ & $4 / 10$ \\
Isolation & $0 / 10$ & $0 / 10$ & $0 / 10$ & $4 / 10$ & $0 / 10$ \\
\hline
\end{tabular}

1- NP: Not performed.

2- HI was performed only in SPA-positive sera.

\section{RAPD}

RAPD allowed to differ MS samples isolated from the reference sample and those obtained from other farms. The comparison of DNA 
amplification patterns in RAPD using the primer 5'-d[GTAGACCCGT]3' (A mersham Pharmacia Biotech) indicated that the MS samples isolated from the same farm were similar. On the other hand, they were different from those obtained in other farms, from the thermolabile vaccine sample $\mathrm{MS} \mathrm{H}$, and also from the reference sample MS WVU 1853, which was used as a diagnosis antigen (Figure 1). No considerable difference was observed in RAPD patterns among the samples studied here and from the pattern showed by samples obtained from other flocks that had been housed in the same farm in recent years. This suggests that the same sample of M S has been in the farm as infecting agent. All MS-positive samples showed the same RAPD profile and seem to be the same.

RAPD results showed that the primer 5'd[GTAGACCCGT]3' may be very useful in epidemiological studies in Brazil, mostly in tracking field samples and identifying vaccine samples.

\section{MS inoculation in SPF birds}

As seen for the follow-up breeder flocks, no clinical sign was seen in the SPF birds inoculated with a MS isolate. No lesion was seen during necropsy in the fourth week after inoculation, when the birds were six-weeks old. Serological conversion was nevertheless considerable, contrary to the results from the field infected flocks. The high infecting dose ( $10^{11}$ per bird) used in the experiment probably caused this difference, but the potential immunogenicity of the studied MS was evident.

Re-isolation of MS was possible from the tracheas. PCR was positive for trachea and air sac swabs, and also in one swab collected from the tarsus-metatarsal joint (Table 6). Since PCR sensitivity is so high, a positive result for a joint swab must be carefully considered, because contamination might have occurred during necropsy and material collection.

Histology showed lymphoid nodules in the trachea and lung, a cuboidal metaplasia and parabronchi lumen stenosis. No lesion was observed in tendons or air sacs. The lesions and the higher number of MS in the trachea suggest that the studied MS caused an infection primarily in that organ. Infections caused by MS with these features have been reported (Droual et al., 1992), although the higher number of case reports refers to joint lesions (M orrow et al., 1998a; Lockabyet al., 1998).
Table 6 - Number of positive results in each technique for samples collected from SPF birds inoculated with M S 451.

\begin{tabular}{lc} 
Test & Positive \\
\hline PSA & $8 / 8$ \\
HI & $8 / 8^{1}$ \\
\hline Trachea - PCR & $5 / 8$ \\
\hline Air sac - PCR & $3 / 8$ \\
\hline M etatarsal extensor tendon - PCR & $1 / 8$ \\
\hline Trachea - isolation & $7 / 8$ \\
\hline Air sac - isolation & $0 / 8$ \\
\hline M etatarsal extensor tendon - isolation & $0 / 8$ \\
\hline
\end{tabular}

1- Geometric mean of titers (GMT): 146.7.

\section{CONCLUSIONS}

MS infection had a predictable profile when free flocks were introduced in a farm with infection history, beginning at rearing and showing no clinical signs. There are greater chances of obtaining evidence of assymptomatic infection using PCR in the first weeks of life, or trying to isolate MS in the onset of egg production. Detection of MS infection based only in serology tests has low reliability and PCR is suggested as the routine technique for epidemiological surveillance.

\section{REFERENCES}

Bashiruddin JB. Extraction of DNA from Mycoplasmas. In: R. M iles, R. Nicholas (editors). Mycoplasma Protocols. Humana Press. 1998. pp.141-144.

Bencina D, Dorrer D, Tadina T. Mycoplasma species isolation from six avian species. Avian Pathology 1987; 16:653-664.

Bradbury J. Identification of M ycoplasmas by Immunofluorescence. In: R. M iles, R. Nicholas (editors). Mycoplasma Protocols. Humana Press. 1998. pp.119-126.

Droual R, Shivaprasad HL, M eteyer CU, Shapiro DP, Walker RL. Severe mortality in broiler chickens associated with M ycoplasma synoviae and Pasteurella gallinarum. Avian Diseases 1992; 36:803-807.

Ewing ML, Cookson KC, Phillips RA, Turner KR, Kleven SH. Experimental infection and transmissibility of M ycoplasma synoviae with delayed serologic response chickens. Avian Diseases 1998; 42:230-238.

Fiorentin L, Balen L, Fialho FB. Patogenicidade de amostras de Mycoplasma synoviae isoladas no Brasil. Arquivo Brasileiro de M edicina Veterinária e Zootecnia 1991; 43:405-410. 
Frey MLL, Hanson LP, Anderson DP. A medium for the isolation of avian mycoplasmas. American Journal of Veterinary Research 1968; 19:2163-2171.

Giambrone JJ, Eidson CS, Kleven SH. Effects of infectious bursal disease on the response of chickens to Mycoplasma synoviae, Newcastle disease virus, and infectious bronchitis virus. American Journal of Veterinary Research 1977; 38:251-253.

Kleven SH. M ycoplasma synoviae infection. In: BW Calnek, HJ Barnes, CW Beard, WM Reid and HW Yoder (editors). Diseases of Poultry, $10^{\text {th }}$ edition. 1997.pp. 220-228.

Kleven SH. Mycoplasmosis. In: DE Swayne (editor). A Laboratory $M$ anual for the Isolation and the Identification of Avian Pathogens, $4^{\text {th }}$ edition. 1998. pp. 74-80.

Kleven SH, Rowland GN, Kumar MC. Poor serologic response to upper respiratory infection with Mycoplasma synoviae in turkeys. Avian Diseases 2001; 45:719-23.

Lauerman LH, Hoerr FJ, Sharpton AR, Shah SM, Van Santen L. Development and application of a polymerase chain reaction assay for M ycoplasma synoviae. Avian Diseases 1993; 37:829-834.

Ley DH, M cLaren JM, Berkhoff JE, Levisohn S. M ycoplasma synoviae strain identification by Random Amplified Polymorphic DNA (RAPD) Analyses. IOM Letters 1998; 5:117.

Lockaby SB, Hoerr FJ, Lauerman HL, Kleven SH. Pathogenicity of Myco plasma synoviae in broiler chicken. Veterinary Pathology 1998; 35:178-190.

Luna LG. M anual of histologic staining methods of the Armed Forces Institute of Pathology. 3ed. New York (NY): McGraw-Hill; 1968.

Marois C, Oufour-Gesbert F, Kempf I. Detection of Mycoplasma synoviae in poultry environment samples by culture and polymerase chain reaction. Veterinary M icrobiology 2000; 73:311-318.

M orrow CJ, Markham JF, Whithear G. Production of temperaturesensitive clones of Mycoplasma synoviae for evaluation as live vaccines. Avian Diseases 1998a; 42:667-670.

M orrow CJ, Bell IG, Walkers SB, Markham PF, Thorp BH, Whitehear $K G$. Isolation of M ycoplasma synoviae from infectious synovitis of chickens. Australian Veterinary Journal 1998b; 67:121-124.

Poveda JB, Carranza J, M iranda A, Garrido A, Hermoso M , Fernandez A, Domenech J. An epizootiological study of avian mycoplasmas in Southern Spain. Avian Pathology 1990; 10:627-633.

Salisch H, Hinz KH, Graack HD, Ryll M. A comparison of a commercial PCR-based test to culture methods for detection of M ycoplasma gallisepticum and M ycoplasma synoviae in concurrently infected chickens. Avian Pathology 1998; 27:142-147.

Silveira RM, Fiorentin L, Marques EK. Polymerase chain reaction optimization for Mycoplasma gallisepticum and Mycoplasma synoviae diagnosis. A vian Diseases 1996; 40:218-222. 
Fiorentin L, Mores MAZ, Trevisol IM, Antunes SC, Costa JLA, Soncini RA,

Test Profiles of Broiler Breeder Flocks Housed in Farms Vieira ND 